\title{
Denoising feedback loops by thresholding-a new role for microRNAs
}

\author{
Stephen M. Cohen, ${ }^{3}$ Julius Brennecke, ${ }^{1}$ and Alexander Stark ${ }^{2}$ \\ European Molecular Biology Laboratory, 69117 Heidelberg, Germany
}

It is almost axiomatic that precision in spatial and temporal control of gene expression is important for organogenesis. Our appreciation of this notion derives in part from studies of the developing sensory nervous system in Drosophila (for review, see Modolell 1997). In this issue of Genes \& Development, Gao and coworkers ( $\mathrm{Li}$ et al. 2006) add an exciting new twist to this story, showing that post-transcriptional gene regulation by the microRNA miR-9a plays an important role in ensuring the precision of sense organ specification in Drosophila.

microRNAs (miRNAs) have gained considerable attention recently as negative post-transcriptional regulators of gene expression (e.g., Ambros 2004; Bartel and Chen 2004; Zamore and Haley 2005; Valencia-Sanchez et al. 2006). miRNAs are an abundant class of noncoding RNAs in animals (Bartel 2004; Berezikov et al. 2005; Xie et al. 2005) and are predicted to target $30 \%$ or more of all animal protein coding genes (Brennecke et al. 2005; Grun et al. 2005; Krek et al. 2005; Lewis et al. 2005; Xie et al. 2005). Likewise, a large number of genes-the so-called anti-targets-are under evolutionary pressure to avoid target sites (Farh et al. 2005; Stark et al. 2005). The investigation of such target and anti-target signatures for miRNAs has recently led to the proposal that miRNAs confer robustness to gene expression (Stark et al. 2005; Hornstein and Shomron 2006), yet few definite functions have been assigned to individual miRNAs to date (Li and Carthew 2005; Krutzfeldt et al. 2005; Sokol and Ambros 2005; Giraldez et al. 2006; Teleman et al. 2006; pre-2005 work reviewed in Ambros 2004; Alvarez-Garcia and Miska 2005).

Li et al. (2006) now report on the function of miR-9a by generating a targeted knockout of the precursor hairpin in Drosophila melanogaster. miR-9a belongs to a highly conserved family of miRNAs found in worms, flies, and vertebrates. In flies, three highly related miR-9 genes have been identified, but during embryogenesis miR-9a is the only one with strong and detectable expression (Aravin et al. 2003; Stark et al. 2005). Flies lacking miR-

Present addresses: ${ }^{1}$ Cold Spring Harbor Laboratory, 1 Bungtown Road, Cold Spring Harbor, NY 11724, USA; ${ }^{2}$ Broad Institute of Massachusetts Institute of Technology and Harvard, Cambridge, MA 02141, USA and Computer Science and Artificial Intelligence Laboratory, Massachusetts Institute of Technology, Cambridge, MA 02139, USA.

${ }^{3}$ Corresponding author.

E-MAIL Stephen.Cohen@embl-heidelberg.de; FAX 49-6221-387-166. Article is online at http://www.genesdev.org/cgi/doi/10.1101/gad.1484606. 9a are viable and fertile, but produce extra sense organs. One of the interesting features of this phenotype is that it is variable both in terms of the number of individuals affected and the severity of the defect. Up to $40 \%$ of mutant embryos show one or more segments with extra larval sense organs. Similarly, $40 \%$ of adults show extra mechanosensory organs (bristles in the wing margin or on the thorax). Careful analysis indicates that these extra sense organs do not arise through cell fate changes within the highly stereotypic sense organ lineage, converting one cell type to another. Instead, Li et al. (2006) provide evidence that the extra sense organs reflect the specification of additional sense organ precursors (SOPs) within existing proneural clusters. How does this happen?

Animal nervous systems derive from neurectodermal progenitor cell populations. Within these populations, subsets of cells are selected to become neurons and glia, whereas the remainder become epidermal. The fundamental mechanisms by which cells are selected and specified to differentiate as neural precursors are conserved in vertebrate and invertebrate embryos (for review, see Bertrand et al. 2002). In Drosophila, sense organ primordia are initially defined as small clusters of cells that express the "proneural" genes, a family of basic helix-loop-helix (bHLH) transcription factors that are essential for neuronal cell fate determination. When these clusters are first specified, the level of proneural gene expression is low, and all cells in a cluster have the capacity to become the SOP. Typically, only one of these cells is selected to become the SOP in a process that involves lateral inhibition through the Notch signaling pathway (for review, see Artavanis-Tsakonas et al. 1999; Bertrand et al. 2002). Selection of the SOP is thought to result from a slight increase in the level of proneural proteins relative to surrounding cells. This leads to increased expression of the zinc-finger transcription factor Senseless, which in turn feeds back positively on proneural gene expression in the presumptive SOP (Nolo et al. 2000). High levels of proneural gene expression in the SOP cell increase the expression of senseless and of the Notch ligand Delta, which activates Notch in surrounding cells of the cluster. Notch signaling leads to repression of proneural gene expression in these cells through bHLH repressors of the E(spl) complex, working together with low levels of Senseless (Jafar-Nejad et al. 2003). 
SOP specification depends on amplification of a subtle initial difference between precursor cells, leading ultimately to a binary cell fate choice. The amplification of cell fate differences is achieved by coupling a transcriptional positive feedback loop with lateral inhibition: The positive feedback loop ensures robust expression of proneural genes and the definitive specification of SOP identity, while lateral inhibition prevents this cell fate in the neighboring cells by repressing proneural gene expression. This model has long been thought to be sufficient to explain the robustness of SOP specification. However, the new findings reported by Li et al. (2006) indicate that the combination of lateral inhibition and the opposing action of the proneural and $\mathrm{E}(\mathrm{spl})$ transcription factors is not sufficient to confer the required degree of precision, and that an additional layer of regulation, provided by miR-9a, is required.

Two lines of evidence pointed to misregulation of the senseless gene as a likely cause of the defects in miR-9a mutants. First, the adult wing phenotype in the mutants closely resembles that of a gain-of-function mutant of the senseless gene (Nolo et al. 2000, 2001). Second, senseless is a computationally predicted target of miR-9a (Enright et al. 2003; Stark et al. 2003; Grun et al. 2005), and $\mathrm{Li}$ et al. (2006) show that miR-9a can repress expression of a luciferase reporter through the senseless $3^{\prime}$ untranslated region (UTR). They also provide strong genetic evidence that senseless is an important miR-9a target in vivo. If the defect in the miR-9a mutant is due to failure to limit Senseless protein levels, the mutant phenotype should be ameliorated by reducing Senseless expression by other means. This is precisely the outcome obtained: Removing one copy of the senseless gene suppressed the adult wing phenotype caused by the miR-9a mutant. Reciprocally, overexpressing miR-9a was able to overcome the production of extra sense organs caused by Gal4-directed overexpression of the senseless gene. Interestingly, the dominant gain-of-function senseless mutant, known as Lyra, lacks part of the 3' UTR, raising the possibility that its excess activity results from escaping regulation due to the lack of miR-9a sites. Verification of this notion will require more direct experimental tests such as removing the miR-9a sites in the context of the endogenous senseless 3' UTR, since molecularly undefined aberrations such as that in Lyra could affect other regulatory elements. It would be also interesting to test whether overexpression of miR-9a is able to suppress sense organ development in the Lyra mutant as effectively as in a normal background.

How can failure to regulate Senseless explain the variable nature of the miR-9a mutant phenotype? If miR-9a were an essential core component of the SOP fate-determining mechanism, we might expect all cells in the proneural cluster to become SOPs in the mutant, as can occur when lateral inhibition is defective. Instead, the outcome is sporadic. This can be explained if the role of miR-9a in this system is to ensure robustness of the underlying switch, rather than functioning as a switch itself (Fig. 1).
During the early proliferative phase, miR-9a is broadly expressed in the neurectodermal territory, from which the neuronal precursor cells derive, and is only subsequently lost in the differentiating neuronal lineage (Stark et al. 2005; Li et al. 2006). High levels of miR-9a could simply prevent premature Senseless expression and hence neural differentiation (Stark et al. 2005). More interestingly, though, when considered in the context of a positive feedback loop, miR-9a could set a threshold that Senseless expression has to overcome in order to trigger the proneural positive feedback system. This threshold might help to select only the highest transcriptional peak(s) while filtering out others that might have been able to surpass the threshold in the absence of the miRNA (Fig. 1). This stochastic property fits well with the observed effects of the miR-9a mutant. Early, miR-9a serves to buffer stochastically fluctuating expression levels, to ensure robustness of what would otherwise be an error-prone switch (Stark et al. 2005; Hornstein and Shomron 2006). When coupled with a positive feedback circuit, miRNAs provide an effective means by which to establish thresholds and limit noise-induced errors. It remains to be seen how general this novel role for miRNAs in "thresholding" will prove to be.

This might also explain how over- or misexpression of miRNAs can cause severe phenotypes. For example, overexpression of miR-9a in the developing thorax region would impose a burden on senseless expression such that the threshold for feedback amplification is only very rarely reached, leading to the loss of most sensory organs in the notum (Li et al. 2006). Therefore, miRNA overexpression phenotypes need not necessarily be explained by strong post-transcriptional inhibition of targets that are persistently transcribed. For example, overexpression of miR-9a in the wing had little or no effect on senseless expression at the wing margin ( $\mathrm{Li}$ et al. 2006), where senseless expression is controlled differently.

A second interesting aspect of how miR-9a participates in this circuit emerges from the spatial relationships that arise later between Senseless and miR-9a expression. During SOP specification, Senseless is expressed at high levels in the SOP cells (Nolo et al. 2000) and at low levels in the surrounding cells of the proneural cluster (Jafar-Nejad et al. 2003), whereas miR-9a is expressed in the surrounding cells, but not in the SOP $(\mathrm{Li}$ et al. 2006). Interestingly, Li et al. (2006) note the presence of proneural gene and Notch-regulated elements in the miR-9a regulatory region, and speculate that miR-9a and $\mathrm{E}(\mathrm{spl})$ complex transcription are controlled similarly. Thus the transition to reciprocal expression of miR-9a and its target senseless may be a facet of the underlying transcriptional switch between proneural and E(spl) expression within the cluster. miR-9a serves to reinforce this difference, but is not sufficient to create it. This situation is reminiscent of the spatial mutual exclusion model, which suggested that miRNAs might contribute to refining nascent primordia by limiting target-gene expression in nearby cells (Stark et al. 2005). 

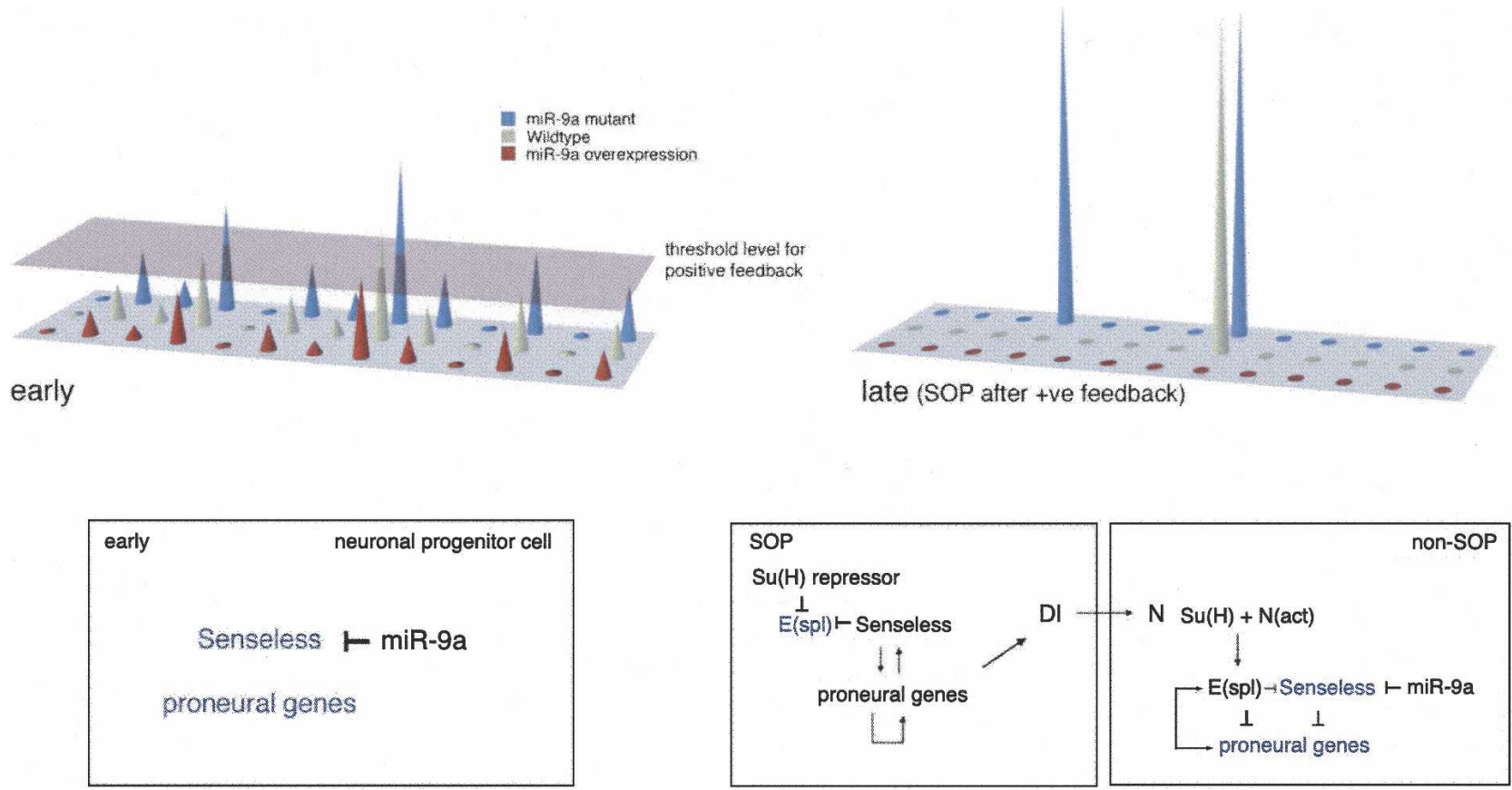

Figure 1. Peak selection by miR-9a during SOP specification in Drosophila. Schematic representation of cells with the different initial levels of Senseless protein expression (cone height) for wild-type (yellow), miR-9a mutant (blue), and miR-9a overexpressing cells (red). Early, miR-9a places a burden on the low and stochastically fluctuating transcription levels of Senseless. In wild-type flies, this means that the threshold for feedback amplification (red plane) is reached only once per proneural cluster. In the absence of miR-9a, stochastically more cells reach the threshold, giving rise to an increase in SOP cells, whereas none of the precursor cells reach the threshold when miR-9a is overexpressed. In cells that pass this threshold, feedback amplification leads to robust Senseless expression, whereas lateral inhibition through Notch signaling prevents Senseless expression in the surrounding cells, which is reinforced by strong miR-9a expression. (+ve) Positive feedback. The regulatory circuitry for the different cells is outlined below. Black denotes strong gene expression/activity. Blue denotes low expression/activity.

Can we expect a comparable function for miR-9 in vertebrates? miR-9a is identical in sequence to the single vertebrate miR-9, which is encoded by at least three distinct loci (Lagos-Quintana et al. 2002). In zebrafish, miR-9 is exclusively expressed in the nervous system, but only in proliferating cells of brain, spinal cord, and eye (Wienholds et al. 2005). A similar expression pattern has recently been reported in mouse embryos (Kloosterman et al. 2006). It is clear that the role of some proneural genes, such as Math1 Ngn1, and others, in specifying neural progenitors by controlling Notch ligand expression is conserved in mice (for review, see Bertrand et al. 2002). In mice, these genes act within a pool of proliferating neurepithelial stem cells, rather than selecting single cells from within an essentially post-mitotic proneural cluster as in the fly. Yet their role is essentially comparable. Considering this, it is striking that miR-9a in flies is expressed in ectodermal cells including the proneural clusters, whereas in vertebrates it is expressed in the proliferating cells of the nervous system. In both cases, miR-9 is expressed in closest proximity to cells that are being selected for neuronal identity. The Senseless orthologs Gfi-1 and Gfi-1B may act together with proneural genes, such as Math1 and Ngn, in cell fate specification (Wallis et al. 2003; Shroyer et al. 2005), but evidence for a general role in neurogenesis is not yet available. Whether miR-9 acts to regulate genes involved in specification of neural differentiation in vertebrates in a manner analogous to Drosophila remains to be determined, but it should be noted that conserved miR-9 target sites have not been predicted in the orthologous transcription factors in mammals (Krek et al. 2005; Lewis et al. 2005). The phenotypic consequences of loss of miR-9 in vertebrates remain a matter for speculation. Overexpression of proneural genes could lead to an increase in neural differentiation. If this occurs too early and interferes with proliferation, we might anticipate a deficit in neurons. If it occurs later, perhaps neurons could be overproduced. The presence of three identical miR-9 genes in mouse will complicate loss-of-function studies by genetics, but recent advances in knockdown of miRNA expression using antagomirs (Krutzfeldt et al. 2005) might provide a means to begin to study the phenotypic consequences of miR-9 loss in vertebrates.

\section{References}

Alvarez-Garcia, I. and Miska, E.A. 2005. MicroRNA functions in animal development and human disease. Development 132: 4653-4662.

Ambros, V. 2004. The functions of animal microRNAs. Nature 431: 350-355.

Aravin, A.A., Lagos-Quintana, M., Yalcin, A., Zavolan, M., Marks, D., Snyder, B., Gaasterland, T., Meyer, J., and Tuschl, T. 2003. The small RNA profile during Drosophila melano- 
gaster development. Dev. Cell 5: 337-350.

Artavanis-Tsakonas, S., Rand, M.D., and Lake, R.J. 1999. Notch signaling: Cell fate control and signal integration in development. Science 284: 770-776.

Bartel, D.P. 2004. MicroRNAs: Genomics, biogenesis, mechanism, and function. Cell 116: 281-297.

Bartel, D.P. and Chen, C.Z. 2004. Micromanagers of gene expression: The potentially widespread influence of metazoan microRNAs. Nat. Rev. Genet. 5: 396-400.

Berezikov, E., Guryev, V., van de Belt, J., Wienholds, E., Plasterk, R.H., and Cuppen, E. 2005. Phylogenetic shadowing and computational identification of human microRNA genes. Cell 120: 21-24.

Bertrand, N., Castro, D.S., and Guillemot, F. 2002. Proneural genes and the specification of neural cell types. Nat. Rev. Neurosci. 3: 517-530.

Brennecke, J., Stark, A., Russell, R.B., and Cohen, S.M. 2005. Principles of microRNAtarget recognition. PLOS Biol. 3: e85.

Enright, A.J., John, B., Gaul, U., Tuschl, T., Sander, C., and Marks, D.S. 2003. MicroRNA targets in Drosophila. Genome Biol. 5: R1.

Farh, K.K., Grimson, A., Jan, C., Lewis, B.P., Johnston, W.K., Lim, L.P., Burge, C.B., and Bartel, D.P. 2005. The widespread impact of mammalian MicroRNAs on mRNA repression and evolution. Science 310: 1817-1821.

Giraldez, A.J., Mishima, Y., Rihel, J., Grocock, R.J., Van Dongen, S., Inoue, K., Enright, A.J., and Schier, A.F. 2006. Zebrafish MiR-430 promotes deadenylation and clearance of maternal mRNAs. Science 312: 75-79.

Grun, D., Wang, Y.L., Langenberger, D., Gunsalus, K.C., and Rajewsky, N. 2005. microRNA target predictions across seven Drosophila species and comparison to mammalian targets. PLoS Comput. Biol. 1: e13.

Hornstein, E. and Shomron, N. 2006. Canalization of development by microRNAs. Nat. Genet. (Suppl.) 38: S20-S24.

Jafar-Nejad, H., Acar, M., Nolo, R., Lacin, H., Pan, H., Parkhurst, S.M., and Bellen, H.J. 2003. Senseless acts as a binary switch during sensory organ precursor selection. Genes \& Dev. 17: 2966-2978.

Kloosterman, W.P., Wienholds, E., de Bruijn, E., Kauppinen, S., and Plasterk, R.H. 2006. In situ detection of miRNAs in animal embryos using LNA-modified oligonucleotide probes. Nat. Methods 3: 27-29.

Krek, A., Grun, D., Poy, M.N., Wolf, R., Rosenberg, L., Epstein, E.J., MacMenamin, P., da Piedade, I., Gunsalus, K.C., Stoffel, M., et al. 2005. Combinatorial microRNA target predictions. Nat. Genet. 37: 495-500.

Krutzfeldt, J., Rajewsky, N., Braich, R., Rajeev, K.G., Tuschl, T., Manoharan, M., and Stoffel, M. 2005. Silencing of microRNAs in vivo with 'antagomirs.' Nature 438: 685-689.

Lagos-Quintana, M., Rauhut, R., Yalcin, A., Meyer, J., Lendeckel, W., and Tuschl, T. 2002. Identification of tissue-specific microRNAs from mouse. Curr. Biol. 12: 735-739.

Lewis, B.P., Burge, C.B., and Bartel, D.P. 2005. Conserved seed pairing, often flanked by adenosines, indicates that thousands of human genes are microRNA targets. Cell 120: 1520.

Li, X. and Carthew, R.W. 2005. A microRNA mediates EGF receptor signaling and promotes photoreceptor differentiation in the Drosophila eye. Cell 123: 1267-1277.

Li, Y., Wang, F., Lee, J.-A, and Gao, F.-B. 2006. MicroRNA-9a ensures the precise specification of sensory organ precursors in Drosophila. 2006. Genes \& Dev. (this issue)

Modolell, J. 1997. Patterning of the adult peripheral nervous system of Drosophila. Perspect. Dev. Neurobiol. 4: 285-296.

Nolo, R., Abbott, L.A., and Bellen, H.J. 2000. Senseless, a Zn finger transcription factor, is necessary and sufficient for sensory organ development in Drosophila. Cell 102: 349362.

Nolo, R., Abbott, L.A., and Bellen, H.J. 2001. Drosophila Lyra mutations are gain-of-function mutations of senseless. Genetics 157: 307-315.

Shroyer, N.F., Wallis, D., Venken, K.J., Bellen, H.J., and Zoghbi, H.Y. 2005. Gfil functions downstream of Math1 to control intestinal secretory cell subtype allocation and differentiation. Genes \& Dev. 19: 2412-2417.

Sokol, N.S. and Ambros, V. 2005. Mesodermally expressed Drosophila microRNA-1 is regulated by Twist and is required in muscles during larval growth. Genes \& Dev. 19: 2343-2354.

Stark, A., Brennecke, J., Russell, R.B., and Cohen, S.M. 2003. Identification of Drosophila microRNA targets. PLOS Biol. 1: E60.

Stark, A., Brennecke, J., Bushati, N., Russell, R.B., and Cohen, S.M. 2005. Animal MicroRNAs confer robustness to gene expression and have a significant impact on 3'UTR evolution. Cell 123: 1133-1146.

Teleman, A.A., Maitra, S., and Cohen, S.M. 2006. Drosophila lacking microRNA miR278 are defective in energy homeostasis. Genes \& Dev. 20: 417-422.

Valencia-Sanchez, M.A., Liu, J., Hannon, G.J., and Parker, R. 2006. Control of translation and mRNA degradation by miRNAs and siRNAs. Genes \& Dev. 20: 515-524.

Wallis, D., Hamblen, M., Zhou, Y., Venken, K.J., Schumacher, A., Grimes, H.L., Zoghbi, H.Y., Orkin, S.H., and Bellen, H.J. 2003. The zinc finger transcription factor Gfil, implicated in lymphomagenesis, is required for inner ear hair cell differentiation and survival. Development 130: 221-232.

Wienholds, E., Kloosterman, W.P., Miska, E., Alvarez-Saavedra, E., Berezikov, E., de Bruijn, E., Horvitz, R.H., Kauppinen, S., and Plasterk, R.H. 2005. MicroRNA expression in zebrafish embryonic development. Science 309: 310-311.

Xie, X., Lu, J., Kulbokas, E.J., Golub, T.R., Mootha, V., LindbladToh, K., Lander, E.S., and Kellis, M. 2005. Systematic discovery of regulatory motifs in human promotersand 3' UTRs by comparison of several mammals. Nature 434: 338-345.

Zamore, P.D. and Haley, B. 2005. Ribo-gnome: The big world of small RNAs. Science 309: 1519-1524. 


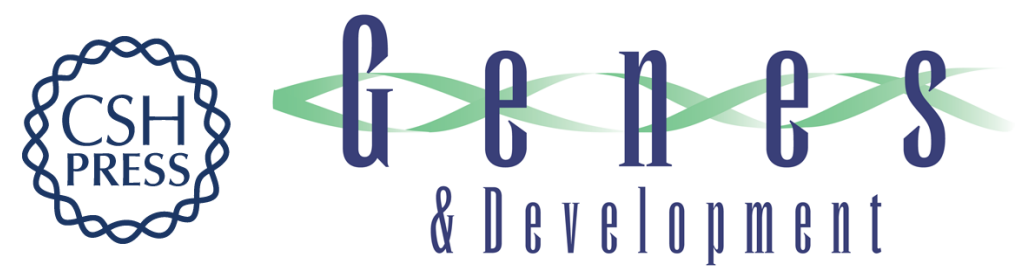

\section{Denoising feedback loops by thresholding-a new role for microRNAs}

Stephen M. Cohen, Julius Brennecke and Alexander Stark

Genes Dev. 2006, 20:

Access the most recent version at doi:10.1101/gad.1484606

\section{Related Content MicroRNA-9a ensures the precise specification of sensory organ precursors in Drosophila Yan Li, Fay Wang, Jin-A Lee, et al. \\ Genes Dev. October, 2006 20: 2793-2805 \\ References This article cites 32 articles, 13 of which can be accessed free at: http://genesdev.cshlp.org/content/20/20/2769.full.html\#ref-list-1 \\ Articles cited in: \\ http://genesdev.cshlp.org/content/20/20/2769.full.html\#related-urls \\ License \\ Email Alerting \\ Receive free email alerts when new articles cite this article - sign up in the box at the top \\ Service right corner of the article or click here.}

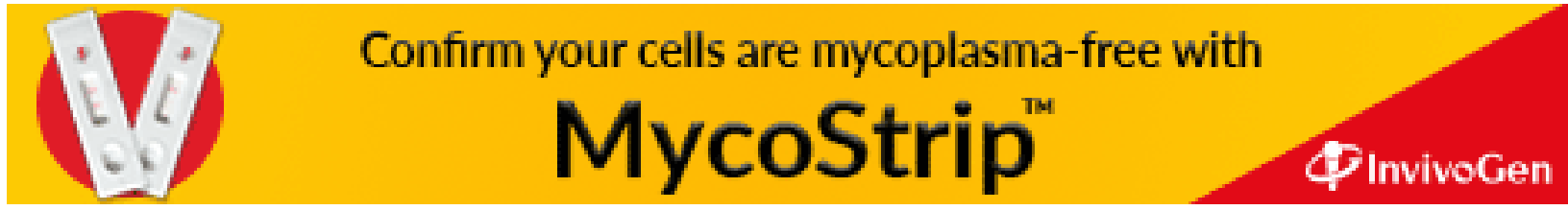

